\title{
A New Method for Predicting Ground Settlement Induced by Pipe Jacking Construction
}

\author{
Zelin Niu, ${ }^{1,2,3}$ Yun Cheng $\mathbb{D}^{1,2}$ Yuwei Zhang $\mathbb{C}^{1,2}$ Zhanping Song $\mathbb{D}^{1,2}$ Guiyang Yang, \\ and $\mathrm{Hui} \mathrm{Li}^{1}$ \\ ${ }^{1}$ School of Civil Engineering, Xi'an University of Architecture and Technology, Xi'an 710055, China \\ ${ }^{2}$ Shaanxi Key Laboratory of Geotechnical and Underground Space Engineering, Xi'an 710055, China \\ ${ }^{3}$ Fifth Engineering Bureau Co., Ltd., China Railway Bridge Engineering Bureau Group Co., Ltd., Chengdu 610000, China
}

Correspondence should be addressed to Yuwei Zhang; 1032659676@qq.com and Zhanping Song; songzhpyt@xauat.edu.cn

Received 4 September 2019; Revised 5 April 2020; Accepted 13 April 2020; Published 7 May 2020

Academic Editor: Mijia Yang

Copyright (c) 2020 Zelin Niu et al. This is an open access article distributed under the Creative Commons Attribution License, which permits unrestricted use, distribution, and reproduction in any medium, provided the original work is properly cited.

Pipe jacking technology has the advantages of fast construction speed, high economic benefit, and small impact on the urban environment, and mechanical vibration and mechanical soil interaction will lead to the settlement of upper part of pipe jacking and surrounding soil. So, the solution of soil settlement problem is of great significance for underground engineering construction. The soil loss, additional stress, and friction during the construction of rectangular pipe jacking are the main factors that cause the surface settlement. Aiming at the problem of surface settlement caused by pipe jacking in no. 6 subway in Kunming, the formation deformation caused by additional stress and friction force on excavation surface during pipe jacking process was analyzed by Mindlin's displacement solution, and the formation deformation caused by soil loss was analyzed by random medium theory. Considering the independence of the three influencing factors, the superposition of the three types of stratum deformation was the superposition model of surface settlement, and the model was compared with the empirical method and the measured settlement data to verify its practicability and reliability. The results showed that the surface vertical settlement curve was roughly in the shape of "S," which can be divided into uplift occurrence area, sensitive settlement area, stable settlement area, and rebound settlement area. Friction force and additional stress caused the uplift of stratum in the front of construction area, and soil loss caused the subsidence of stratum in the rear of construction area. Rectangular pipe jacking in weak stratum caused the soil to move towards the excavation surface, easily causing micro-overexcavation.

\section{Introduction}

With the continuous development and utilization of urban underground space, such as tunnel, underground station, and underground commercial space [1-3], the construction of many underground facilities has gradually failed to meet the requirements of open-cut construction [4-7]. Pipe jacking is one of the typical trenchless underground construction methods $[8,9]$, which has the advantages of high utilization rate of section area, shallow burial depth, no interruption of surface traffic, high efficiency, and low pollution. By integrating factors such as equipment composition, construction technology, construction speed, and social and economic benefits, pipe jacking has obvious advantages in the construction of underground channels $[10,11]$. However, due to the vibration of soil (rock) body and interaction between mechanical and rock body caused by mechanical construction, soil loss, additional stress on end face, and friction force in pipe jacking construction will inevitably produce surface settlement [12-15], which seriously threatens the safety of surrounding existing buildings (structures). With the development of pipe jacking technology, rectangular pipe jacking is gradually applied, and the surface settlement caused by rectangular pipe jacking is different from that caused by circular pipe jacking. Therefore, it is of great significance to clarify and solve the surface settlement caused by rectangular pipe jacking for the development of modern underground space engineering. 
At present, many scholars have studied the surface settlement caused by pipe jacking, and the research methods mainly include theoretical analysis, field measurement, and numerical analysis. Because the theoretical research and engineering application of circular pipe jacking have been gradually mature, the rectangular pipe jacking mainly uses the calculation method of circular pipe jacking for reference. As for the research status of the surface settlement in the current subway construction, the results obtained from the three aspects of theoretical analysis, field measurement, and numerical simulation are analyzed as follows.

1.1. Theoretical Analysis. The peak empirical formula method was the most widely used and first proposed the quasi-normal distribution of lateral surface settlement estimation method in 1969. Attewell and Farmer [16, 17] analyzed the longitudinal surface settlement of shield excavation and proposed the method of cumulative probability curve to estimate the longitudinal surface settlement. Ren et al. [18] put forward a calculation method of surface settlement caused by circular pipe jacking construction and carried out case analysis. Cheng et al. [19] conducted a systematic analysis of the variation law of jacking force when the earth-pressure-balanced pipe jacking machine traverses different strata according to the pipe jacking construction project in Taiwan. Sagaseta [20] provided the surface strain solution in the case of surface loss caused by elastic isotropic homogeneous mass. Verruijt and Booker [21] considered the elliptical deformation under the initial stress field and modified Sagaseta's method. Wei et al. [22] used Mindlin's elastic theory solution and deduced the formula for calculating the ground deformation caused by the additional thrust on the front of circular pipe jacking and the lateral friction resistance of pipe jacking machine and subsequent pipe joints. Based on the random medium theory, Han [23] deduced the calculation formulas of various section shapes in the nonuniform convergence mode.

1.2. Field Measurement. To meet the safety and efficient construction requirements in the process of urban subway tunnel construction, Sun et al. [24] used field monitoring method to analyze key parameters such as pore water pressure, jacking force, and earth pressure in pipe jacking construction of double-line underground pedestrian channel. Zhang et al. [25] summarized four jacking force calculation methods and carried out the field test about the jacking force during the pipe jacking construction process of Gongbei tunnel, and the comparative analysis was carried out with the theoretical calculation method. Relying on a pipe jacking project in Chongqing, Li et al. [26] tested the damage of large-section concrete pipe segments on-site and conducted systematic analysis in parallel.

1.3. Numerical Simulation. Lin [27] used MARC program to study the influence of rectangular pipe jacking construction of Shanghai metro line 6 on surface settlement at different burial depths. Bing et al. [28] simulated the actual working conditions and found that the influence ranges of transverse and longitudinal surface deformation caused by circular pipe jacking were $-3.6 \sim 3.6 D$ and $-2.14 \sim 2.14 D$, respectively ( $D$ was the external diameter of pipe joints). Tang et al. [29] took the construction of the first rectangular subway shield in China as the background and adopted ABAQUS three-dimensional finite element simulation software to simulate the actual project. It can be seen that, compared with the more mature circular pipe jacking, the development of rectangular pipe jacking is not yet mature, which is still a new technology of underground space construction.

From the above research results, it can be seen that many experts have paid attention to the ground surface settlement of soil mass and rock mass in the process of tunnel construction and have obtained abundant research results. Previous studies on the soil deformation caused by rectangular pipe jacking mainly refer to shield construction and circular section pipe jacking. Moreover, the surface settlement law and prediction of rectangular pipe jacking construction caused by soil loss, additional stress, and friction force are rarely reported. Because of the great difference of cross-sectional shape between circular and rectangular pipe jacking construction, the soil stress variation form and random movement mode are quite different. In the face of the gradual popularization of rectangular pipe jacking technology, its theoretical research is inevitably greatly different from that of circular pipe jacking and shield construction, which puts forward higher requirements for the study of stratum subsidence caused by rectangular pipe jacking.

The rectangular top pipe project of the underground connection passage between Tuodong stadium station on line 6 of Kunming metro and Tuodong Dacheng central business district is located at the intersection of Tuodong road and east Huancheng road, with busy surface traffic and numerous underground pipelines, not meeting the construction conditions of open excavation. Considering the complex construction environment comprehensively, the project plans to adopt the rectangular pipe jacking machine with multiblade-earth pressure balance for tunneling construction. In this study, the influence of soil loss, additional stress on end face, and friction force on surface settlement during construction was comprehensively considered. The surface settlement caused by rectangular pipe jacking was divided into three parts, namely, the settlement caused by soil loss, the settlement caused by additional stress on end face, and the settlement caused by friction force. Then, based on the basic hypothesis of the superposition model, Mindlin's elastic theory and random medium theory were used to solve the surface settlement equation caused by various factors, and the superposition model was obtained after the three kinds of settlement were added. Finally, according to the established settlement model, the empirical method, and the measured settlement amount, the surface settlement deformation characteristics caused by the rectangular pipe jacking construction disturbance were studied. 


\section{Soil Stress Characteristics and Basic Assumptions}

2.1. Analysis of Soil Force Characteristics. A number of factors in pipe jacking construction can affect the final surface subsidence, the transverse pressure (the additional stress is provided to make the excavation face stable in pipe jacking construction process) of end face and wall friction (the larger friction between the subsequent pipe section and digger propulsion process), and ground subsidence caused by soil loss (soil loss caused by overexcavation of the earth body around the pipeline) are most obvious. Therefore, this paper mainly analyzes the surface settlement caused by the above three factors in the construction of rectangular pipe jacking and assumes that the final surface settlement is the superposition of the three settlement amounts.

Son and Peck [16] analyzed a large number of engineering data and believed that under the condition of undrained soil mass, the volume of surface settlement trough caused by soil mass loss was the same as that of soil layer loss, and the surface settlement trough was normally distributed in a curve. The lateral surface settlement is

$$
\left\{\begin{array}{l}
S(x)=S_{\text {max }} \exp \left(-\frac{x^{2}}{2 i^{2}}\right), \\
S_{\text {max }}=\frac{V_{\text {loss }}}{\sqrt{2 \pi} i} \approx \frac{V_{\text {loss }}}{2.5 i},
\end{array}\right.
$$

where $S(x)$ is the lateral surface settlement $(\mathrm{m})$ caused by soil loss; $x$ is the horizontal distance $(\mathrm{m})$ from the calculated point to the pipe jacking axis; $S_{\max }$ is the maximum surface settlement value (appearing above the pipe jacking axis) (m); and $V_{\text {loss }}$ refers to the formation loss per unit length in the tunneling process. For clay, it is usually $0.5 \sim 2.5 \%$ of the excavation area (A). $K$ is the percentage of soil loss and soil loss $V_{\text {loss }}=A k\left(\mathrm{~m}^{3} /\right.$ $\mathrm{m}) ; i$ is settlement trough coefficient $(\mathrm{m})$. Verruijt and Booker [21] believed that when $3 \mathrm{~m}<h<34 \mathrm{~m}$, the empirical formula of $i$ was $i=0.43 h+1.10$ (clay), $i=0.28 h-0.10$ (granular soil).

However, among the many factors that cause surface subsidence during the construction of the top pipe, Peck's empirical formula only considers the surface settlement caused by the vertical movement of soil caused by formation loss, but does not consider the surface settlement caused by the three-dimensional displacement and stress change of soil within a certain range. Therefore, based on Mindlin's solution [22, 30, 31] and random medium theory [16], this paper proposes a superposition model of surface subsidence under the combined action of three factors:

$$
\omega=\omega_{1}+\omega_{2}+\omega_{\text {loss }},
$$

where $\omega$ is the total surface settlement value $(\mathrm{m}) ; \omega_{1}$ is surface settlement $(\mathrm{m})$ caused by end pressure; $\omega_{2}$ is the surface subsidence caused by friction ( $\mathrm{m})$; and $\omega_{\text {loss }}$ is ground subsidence $(\mathrm{m})$ caused by soil loss.

2.2. Basic Assumptions of the Model. Force analysis of pipe jacking construction is shown in Figure 1, which is mainly

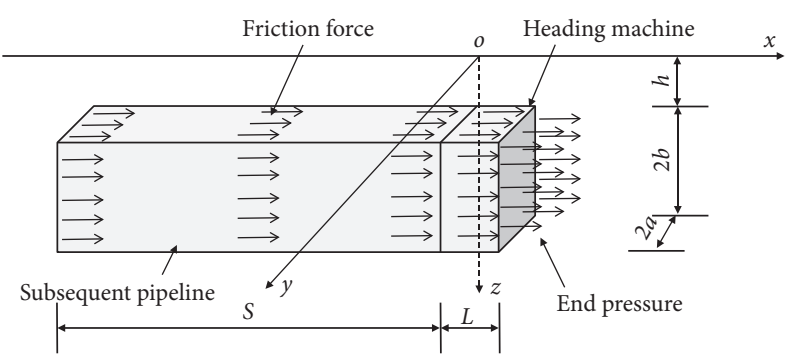

FIgURE 1: Schematic diagram of soil force characteristics.

caused by the sectional reaction force of the jacking face and friction force of the pipe wall. Based on the stress region integral based on Mindlin's solution, the ground settlement caused by stress can be obtained, and the ground settlement caused by soil loss can be considered to obtain the ground settlement during pipe jacking.

During the construction of pipe jacking, the superposition model of surface settlement includes five basic assumptions. (1) During construction, the digger digs in a straight line in the normal solidification soft soil, regardless of the influence of factors such as correction and slurry pressure. (2) The soil mass is a uniform linear elastic semiinfinite body, which is consolidated under the condition of no drainage. (3) The tunneling of tunneling machine in the construction process is only the change of space position, which has nothing to do with time. (4) The front end of the roadheader is the load action surface, and the end pressure is approximately rectangular uniform load. (5) According to its position, the friction force of tunneling machine and subsequent pipe joints is divided into upper surface friction, lower surface friction, left-side friction, and right-side friction. The friction resistance of upper and lower surface is the product of normal stress and friction coefficient of soil, and the friction resistance of left and right side is the product of active soil pressure and friction coefficient.

Based on the above five basic assumptions, in the process of rectangular pipe jacking, the derivation of surface subsidence $\omega_{1}, \omega_{2}$, and $\omega_{\text {loss }}$ is caused by the three factors, respectively, shown in Section 3.1. Since the rectangular top pipe has four surfaces, namely, upper, lower, left, and right, the corresponding surface subsidence caused by the four kinds of friction are, respectively, expressed as $\omega_{21}, \omega_{22}, \omega_{23}$, and $\omega_{24}$.

\section{Superposition Model of Surface Subsidence}

3.1. Surface Settlement Caused by End Pressure. As can be seen from Figure 1, it can be known that the area where the additional stress on the end surface acts on the soil is the continuous plane of $\left\{\begin{array}{l}-a \leq y \leq a \\ h \leq z \leq h+2 b . \\ x=0\end{array}\right.$ To distinguish the calculated point coordinate and the integral variable, the integral variable $(x, y, z)$ was replaced by $(l, m, n)$, and the microelement $\mathrm{d} m \mathrm{~d} n$ was taken from the action plane of the additional stress on the end surface, and then the ground settlement caused by the stress in the differential area was solved by Mindlin's solution. Since the surface settlement is 
discussed in this paper, the calculated depth is zero (i.e., $z=0$ ). The surface settlement caused by end stress is

$$
\omega_{1}=\frac{P_{1} x}{4 \pi G} \int_{-a}^{a} \int_{0}^{2 b} \frac{1}{M_{1}}\left(\frac{1-2 \mu}{M_{1}+h+n}-\frac{h+n}{M_{1}^{2}}\right) \mathrm{d} m \mathrm{~d} n,
$$

where $\omega_{1}$ is surface settlement $(\mathrm{m})$ caused by end face stress; $x$ is the horizontal distance $(\mathrm{m})$ from the calculated point to the excavation face, and the jacking direction is positive. $y$ is the horizontal distance $(\mathrm{m})$ from the calculated point to the axis, both of which are positive. $h$ is the distance from the top surface of the pipe jacking to the ground (m); $2 a$ is end face width (m) of roadheader; $2 b$ is the face height of the roadheader $(\mathrm{m}) ; P_{1}$ is the additional stress on the face of roadheader $(\mathrm{kPa})$; and $G$ is soil shear elastic modulus (MPa). $G=(1-2 \mu) E_{\mathrm{so}} /[2(1+\mu)]$, where $E_{\mathrm{so}}$ is soil compression modulus, $\mu$ is soil Poisson's ratio, and $K_{0}$ is static earth-pressure coefficient [22]. $K_{0}=\mu /(1-\mu)$, $M_{1}=\left[x^{2}+(y-m)^{2}+(h+n)^{2}\right]^{0.5}$.

3.2. Surface Settlement Caused by Friction. The friction generated during pipe jacking mainly includes two parts: one is the friction between the side wall of the roadheader and soil mass, and the other is the friction between the subsequent pipe joints and soil mass. In the construction process, the tunneling machine is in close contact with soil mass, and there is a layer of thixostatic mud sleeve between subsequent pipe joints and surrounding soil mass, so the lubrication effect of grouting sleeve should be considered when calculating the friction force between subsequent pipe joints and soil mass. At the same time, considering the small difference between the outside dimension of roadheader and the outside dimension of pipe section, it can be assumed that the size of pipe section is equal to the section size of roadheader. The calculation method of surface settlement caused by friction force is similar to that caused by end pressure. However, when integrating Mindlin's solution in this case, it should be noted that the four faces of roadheader and subsequent pipe joints are discontinuous and smooth, so the four faces of upper, lower, left, and right need to be integrated, respectively.

3.2.1. Surface Settlement Caused by Upper Surface Friction. As can be seen from Figure 1, the area of friction acting on the upper surface of the pipe section is a continuous plane of $\left\{\begin{array}{l}-S \leq x \leq 0 \\ -a \leq y \leq a . \\ z=h\end{array}\right.$ the roadheader and the subsequent pipe section is different from that produced by the soil mass, it needs to be solved in sections. Take the microelement $\mathrm{d} l \mathrm{~d} m$ on the upper surface, and the surface settlement caused by friction on the upper surface is

$$
\begin{aligned}
\omega_{21}= & \frac{P_{2} f_{1}}{4 \pi G} \int_{-a}^{a} \int_{-L}^{0} \frac{x-l}{M_{2}}\left(\frac{1-2 \mu}{M_{2}+h}-\frac{h}{M_{2}^{2}}\right) \mathrm{d} l \mathrm{~d} m \\
& +\frac{\alpha P_{2} f_{2}}{4 \pi G} \int_{-a}^{a} \int_{-S}^{-L} \frac{x-l}{M_{2}}\left(\frac{1-2 \mu}{M_{2}+h}-\frac{h}{M_{2}^{2}}\right) \mathrm{d} l \mathrm{~d} m,
\end{aligned}
$$

where $\omega_{21}$ is the surface settlement caused by friction on the upper surface (m); $L$ is length of roadheader $(\mathrm{m}) ; S$ is the distance from the end face of the tunneling machine to the tunneling starting point $(\mathrm{m}) ; P_{2}$ is the upper pressure of tube jacking $(\mathrm{kPa}), P_{2}=\gamma h ; a$ is the friction reduction coefficient between soil and pipe joints under thixotropic mud; $f_{1}$ is the friction coefficient between roadheader and soil mass; $f_{2}$ is the friction coefficient between pipe joint and soil mass; and $M_{2}=\left[(x-1)^{2}+(y-m)^{2}+h^{2}\right]^{0.5}$.

\subsubsection{Surface Settlement Caused by Lower Surface Friction.} Since the lower surface of the pipe joint and the upper surface are parallel, and the depth difference is $2 b$, the pressure of the lower soil after excavation is the sum of the pressure of the upper Earth and the pressure of the roadheader (pipe joint) on the soil. Therefore, when deducing the surface displacement and settlement caused by the lower surface friction, it is only necessary to replace the upper Earth pressure $P_{2}$ in equation (4) with the lower earth pressure $P_{3}\left(P_{4}\right)$ after tunneling and the upper depth $h$ with the lower depth $h+2 b$. The surface settlement caused by the lower surface friction is

$$
\begin{aligned}
\omega_{22}= & \frac{P_{3} f_{1}}{4 \pi G} \int_{-a}^{a} \int_{-L}^{0} \frac{x-l}{M_{3}}\left(\frac{1-2 \mu}{M_{3}+h+2 b}-\frac{h+2 b}{M_{3}^{2}}\right) \mathrm{d} l \mathrm{~d} m \\
& +\frac{\alpha P_{4} f_{2}}{4 \pi G} \int_{-a}^{a} \int_{-S}^{-L} \frac{x-l}{M_{3}}\left(\frac{1-2 \mu}{M_{3}+h+2 b}-\frac{h+2 b}{M_{3}^{2}}\right) \mathrm{d} l \mathrm{~d} m,
\end{aligned}
$$

where $\omega_{22}$ is the surface settlement $(\mathrm{m})$ caused by the lower surface friction; $P_{3}$ is the earth pressure $(\mathrm{kPa})$ on the bottom surface of the roadheader; $P_{4}$ is the earth pressure $(\mathrm{kPa})$ on the lower surface of the concrete pipe section; and $M_{3}=[(x-l)$ $\left.{ }^{2}+(y-m)^{2}+(h+2 b)^{2}\right]^{0.5} \cdot P_{3}$ and $P_{4}$ are expressed as follows:

$$
\left\{\begin{array}{l}
P_{3}=\gamma h+\frac{T_{j}}{2 a \mathrm{~L}}, \\
P_{4}=\gamma h+\frac{T_{g}}{2 a s},
\end{array}\right.
$$

where $T_{j}$ is the weight of roadheader $(\mathrm{kN}) ; T_{g}$ is concrete pipe joint weight $(\mathrm{kN})$; and $s$ is the length of single concrete $(\mathrm{m})$.

\subsubsection{Surface Settlement Caused by Left Surface Friction.} As the left and right surfaces of the tube jacking are vertically parallel, the distribution of friction force on the left and right surfaces can be considered to be identical when other minor influencing factors are ignored. It is assumed that the lateral pressure of soil on the left and right sides is $P_{5}(\mathrm{kPa})$, and that the lateral pressure of soil increases with the increase of depth. Therefore, $P_{5}$ is a function of soil depth. The expression of $P_{5}$ is

$$
P_{5}=K_{1}(h+n) \gamma .
$$

According to Figure 2, the area affected by the friction force on the left surface of the tube jacking is a continuous plane of $\left\{\begin{array}{l}-S \leq x \leq 0 \\ h \leq z \leq h+2 b . \\ y=a\end{array}\right.$ 


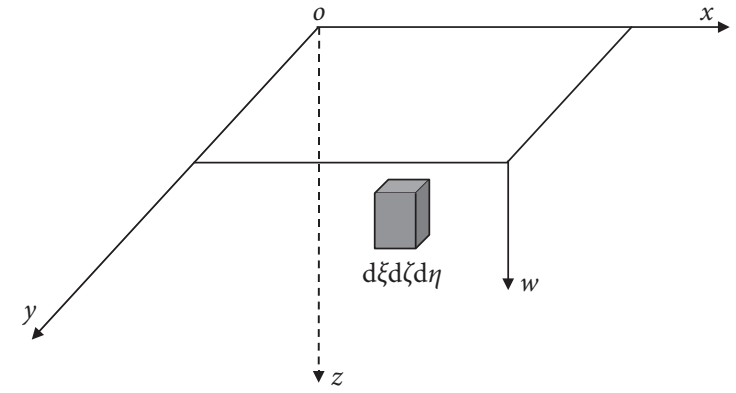

Figure 2: Schematic diagram of unit excavation.

surface, the surface settlement caused by friction on the left surface is

$$
\begin{aligned}
\omega_{23}= & \frac{f_{1}}{4 \pi G} \int_{0}^{2 b} \int_{-L}^{0} \frac{P_{5}(x-l)}{M_{4}}\left(\frac{1-2 \mu}{M_{4}+h+n}-\frac{h+n}{M_{4}^{2}}\right) \mathrm{d} l \mathrm{~d} n \\
& +\frac{\alpha f_{2}}{4 \pi G} \int_{0}^{2 b} \int_{-S}^{-L} \frac{P_{5}(x-l)}{M_{4}}\left(\frac{1-2 \mu}{M_{4}+h+n}-\frac{h+n}{M_{4}^{2}}\right) \mathrm{d} l \mathrm{~d} n,
\end{aligned}
$$

where $\omega_{23}$ is the surface settlement $(\mathrm{m})$ caused by left surface friction; $M_{4}=\left[(x-l)^{2}+(y-a)^{2}+(h+n)^{2}\right]^{0.5}$.

The right-side frictional force and the left-side frictional force are only $2 a$ apart in position and symmetric about the $x o z$ plane. Therefore, when deducing the formula of surface displacement and settlement caused by friction on the right side, it is only necessary to replace $a$ in the above equation with $-a$, and the amount of surface settlement caused by the right side during jacking is

$$
\begin{aligned}
\omega_{24}= & \frac{f_{1}}{4 \pi G} \int_{0}^{2 b} \int_{-L}^{0} \frac{P_{5}(x-l)}{M_{5}}\left(\frac{1-2 \mu}{M_{5}+h+n}-\frac{h+n}{M_{5}^{2}}\right) \mathrm{d} l \mathrm{~d} n \\
& +\frac{\alpha f_{2}}{4 \pi G} \int_{0}^{2 b} \int_{-S}^{-L} \frac{P_{5}(x-l)}{M_{5}}\left(\frac{1-2 \mu}{M_{5}+h+n}-\frac{h+n}{M_{5}^{2}}\right) \mathrm{d} l \mathrm{~d} n,
\end{aligned}
$$

where $\omega_{24}$ is the surface settlement caused by left surface friction $(\mathrm{m}) ; M_{5}=\left[(x-l)^{2}+(y+a)^{2}+(h+n)^{2}\right]^{0.5}$.

Therefore, based on equations (4) (9), it can be known that the surface settlement caused by tube jacking friction is the sum of the surface settlement caused by upper, lower, left, and right surface friction.

3.3. Surface Settlement Caused by Soil Loss. Soil mass loss during pipe jacking refers to actual excavation of the soil body more than the design of the earth body. The main reason for soil mass loss is that there is a gap of about $5 \mathrm{~cm}$ in the construction building during construction (the difference between the size of the tunneling head and the size of the pipe joints). With the gradual optimization of construction technology and grouting effect, soil loss has been well controlled but still inevitable, resulting in surface settlement.
A large number of measured results show that the soil mass around the pipe jacking has an obvious movement trend during the tunneling process. The soil mass cannot be regarded as a simple elastomer or elastoplastic body under general conditions, and the traditional mechanical model analysis method is no longer applicable to the soil mass movement state. Due to the complicated control factors of soil mass movement, soil mass can be used as random medium according to random medium theory. As shown in Figure 2, the unit's infinitesimal length, width, and height are defined as the excavation units, and the surface settlement caused by excavation is expressed as $\omega_{\text {loss }}$. Under the condition of no drainage, the final settlement tank volume and soil loss volume are the same. Therefore, when the excavation unit completely collapses, the settlement tank volume is $\mathrm{d} \xi \mathrm{d} \zeta \mathrm{d} \eta$, and the spatial rectangular coordinate system is established with the excavation unit center; then the settlement amount of the upper soil mass is

$$
\omega_{\text {loss }}=\frac{1}{r^{2}(z)} \exp \left[-\frac{\pi}{r^{2}(z)}\left(x^{2}+y^{2}\right)\right] \mathrm{d} \xi \mathrm{d} \zeta \mathrm{d} \eta
$$

where $\omega_{\text {loss }}$ is the surface settlement $(\mathrm{m})$ caused by soil loss; $r(z)$ is the influence radius of excavation unit in the $z$-direction, $r(z)=z / \tan \beta$; and $\beta$ is the soil influence angle on the top of pipe jacking, $\tan \beta=h /(2.50 i)$ [19]. According to the random medium theory, when the excavation face completely collapses, the soil loss area is taken as the integral domain, and the settlement value at any point on the surface can be obtained by integrating equation (10). The schematic diagram of soil loss is shown in Figure 3.

In fact, the volume of soil collapse during pipe jacking is equal to the volume of soil loss. It is assumed that the loss area of engineering soil is a rectangular ring of equal thickness set outside the excavation face (due to the influence of gravity and grouting and other factors, the gap on the lower side of the pipe section is transferred to the upper side, as shown in Figure 3(b)). To simplify the calculation, the square area at the four corners of the rectangle ring is ignored, and then the relational expression is

$$
4 a \Delta t+4 b \Delta t=A \kappa
$$

So,

$$
\Delta t=\frac{A \kappa}{4(a+b)} .
$$

By integrating the soil loss area shown in Figure 3, the expression of surface settlement caused by soil loss can be obtained as follows:

$$
\omega_{\text {loss }}=\iint_{\Omega} d \zeta \mathrm{d} \eta \int_{-S}^{-L} \frac{\tan ^{2} \beta}{\eta^{2}} \exp \left\{-\frac{\pi \tan ^{2} \beta}{\eta^{2}}\left[(x-\xi)^{2}+(y-\zeta)^{2}\right]\right\} \mathrm{d} \xi .
$$

After substituting equation (12) into equation (13), we can obtain 


$$
\begin{aligned}
\omega_{\text {loss }}= & \int_{h+2 b+\Delta t}^{h-\Delta t} \int_{-a-\Delta t}^{a+\Delta t} \int_{-S}^{-L} \frac{\tan ^{2} \beta}{\eta^{2}} \exp \left\{-\frac{\pi \tan ^{2} \beta}{\eta^{2}}\left[(x-\xi)^{2}\right.\right. \\
& \left.\left.+(y-\zeta)^{2}\right]\right\} \mathrm{d} \zeta \mathrm{d} \eta \mathrm{d} \xi-\int_{h+2 b+\Delta t}^{h+\Delta t} \int_{-a}^{a} \int_{-S}^{-L} \frac{\tan ^{2} \beta}{\eta^{2}} \exp \\
& \cdot\left\{-\frac{\pi \tan ^{2} \beta}{\eta^{2}}\left[(x-\xi)^{2}+(y-\zeta)^{2}\right]\right\} \mathrm{d} \zeta \mathrm{d} \eta \mathrm{d} \xi .
\end{aligned}
$$

3.4. Surface Settlement Overlay Model during Rectangular Pipe Jacking. By substituting equations (3)-(5), (8), (9), and (14) into equation (2), the surface settlement during the construction period of rectangular pipe jacking can be expressed as follows:

$$
\omega=\omega_{1}+\omega_{21}+\omega_{22}+\omega_{23}+\omega_{24}+\omega_{\text {loss }} .
$$

\section{Analysis and Discussion of Models}

4.1. Physical and Mechanical Indexes of Foundation and Soil Layer. The connection channel between Tuodong stadium station of Kunming metro line 6 and Dacheng business district is located under the intersection of Huancheng south road and Tuodong road in Kunming, Yunnan province. The excavation face is mainly composed of clay, clayey silty soil, and silty clay layer, with high groundwater level and complicated geological conditions. Soil distribution, concrete pipe joints, and pipe jacking machine cutterhead of the stratum where the pipe jacking channel is located are shown in Figure 4. Physical parameters of each soil layer [32] are shown in Table 1. The cohesive force and internal friction angle are obtained under the condition of undrainage, which is consistent with the test conditions of the natural capacity. To facilitate calculation, physical parameters of soil layer are calculated according to the average value. The total length of pipe jacking in this project is about $98.08 \mathrm{~m}$, the depth of overlaying is about $5.50 \mathrm{~m}$, and the pipe jacking joints are made of concrete pipes with outer dimensions of $4.90 \mathrm{~m} \times 6.90 \mathrm{~m}$, pipe thickness of $0.45 \mathrm{~m}$, and mass of $39 t$, and the design slope is $1 \%$. A rectangular pipe jacking machine with an external size of $5 \mathrm{~m} \times 7 \mathrm{~m}$ and a mass of $165 t$ is adopted for construction. In order to ensure the stability of the excavation face, the additional stress on the end face is $20 \mathrm{kPa}$. In addition, friction coefficient between concrete roof wall and soil mass is shown in Table 2.

4.2. Analysis of Surface Lateral Settlement. According to the calculation of jacking force on-site, the friction between soil mass and pipe joints after grouting is about $30 \sim 40 \%$ of the original friction force, so the reduction factor $\alpha=0.35$ is taken in this paper. With the MATLAB software, Peck's empirical formula and the calculation model in this paper were compared to obtain the land surface settlement value caused by various factors and the final overall land surface settlement value. In this paper, $45 \mathrm{~m}$ jacking of roadheader is selected for calculation and data comparison analysis. Positive values indicate subsidence and negative values indicate uplift.

Figures 5-7 show the lateral surface deformation curves under the separate and combined action of formation loss, end stress, and friction when $x=3 \mathrm{~m}, x=0 \mathrm{~m}$, and $x=-3 \mathrm{~m}$, respectively. It can be seen from Figures 5-7 that the maximum value of surface settlement or uplift caused by various factors appears directly above the pipe jacking axis, and the change curve is symmetric with respect to the pipe axis. When soil loss is the main control factor, the lateral surface settlement caused by it has a strong response to distance, and the influence range is mainly within $10 \mathrm{~m}$ on the left and right sides of the vertical axis. When end pressure and friction are the main control factors, the lateral surface settlement caused by it has a relatively mild response to the distance, and the influence scope is mainly concentrated in the range of $15 \mathrm{~m}$ on the left and right sides of the vertical axis of the pipeline. It can also be seen that the amount of surface settlement caused by end pressure and friction is small.

4.3. Analysis of Surface Longitudinal Settlement. Figure 8 shows the longitudinal surface settlement curve under the separate and combined action of soil loss, end pressure, and friction when $y=0 \mathrm{~m}$. According to the analysis in Figure 8, when soil loss is the main control factor, a large surface settlement is generated behind the roadheader.

According to the settlement calculation model in this paper, significant settlement still occurs within $1.50 \mathrm{~m}$ from the nose of the roadheader to the front, and the change rate is fast. When the end face additional stress and friction for the main control factors, the surface subsidence change caused by it is small, face additional stress in the excavation front end causes surface uplift and in the back end causes the surface subsidence. The ground settlement change is angled antisymmetric of excavation. The friction force mainly affects the surface change within $9 \mathrm{~m}$ of the front of the excavation and makes the surface swell up.

Longitudinal changes of the surface under the combined action of the three factors (based on the calculation model of surface settlement derived in this paper): the surface about $1.50 \mathrm{~m}$ in front of excavation is shown as uplift, with the maximum uplift of $5.15 \mathrm{~mm}$, occurring at $6 \mathrm{~m}$ in front of excavation. The main control factors are additional pressure and friction on the end face. Settlement occurs after the roadheader with the maximum settlement of $32.63 \mathrm{~mm}$ occurring at $9 \mathrm{~m}$ behind the roadheader, and the settlement decreases to some extent after that. The main control factor is soil loss. On the whole, the surface longitudinal settlement change curve is roughly in the shape of " $\mathrm{S}$ " and can be divided into four areas according to its change trend: uplift occurrence area, sensitive settlement area, settlement stability area, and settlement rebound area.

4.4. Comparative Analysis of Theoretical Calculation and Field Measured Data. To verify the reliability of the calculation 


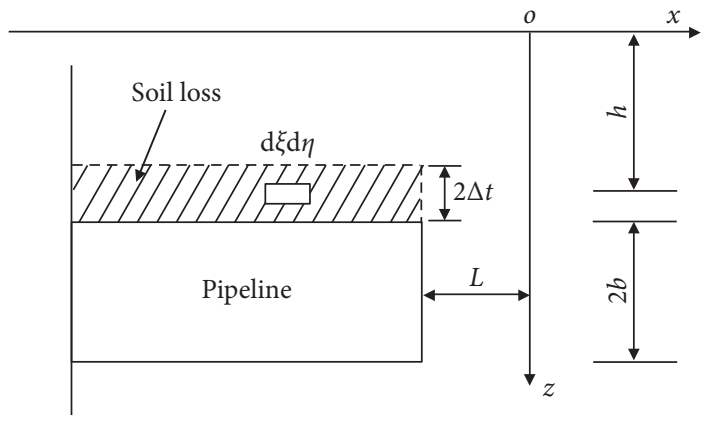

(a)

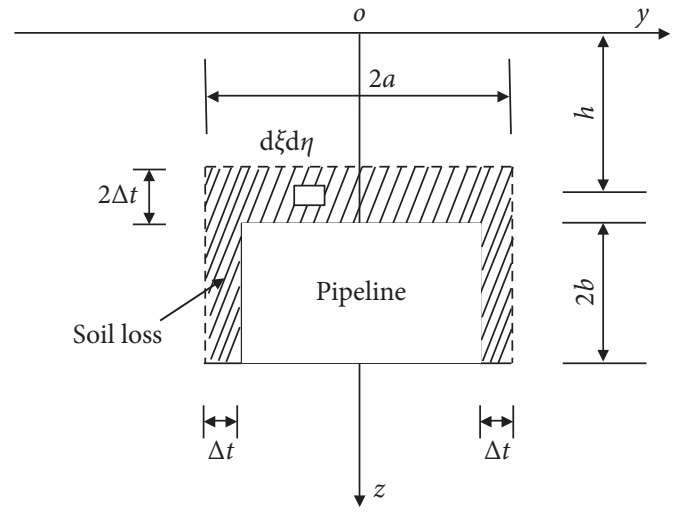

(b)

Figure 3: Schematic diagram of soil loss. (a) Longitudinal soil loss map. (b) Transverse soil loss map.

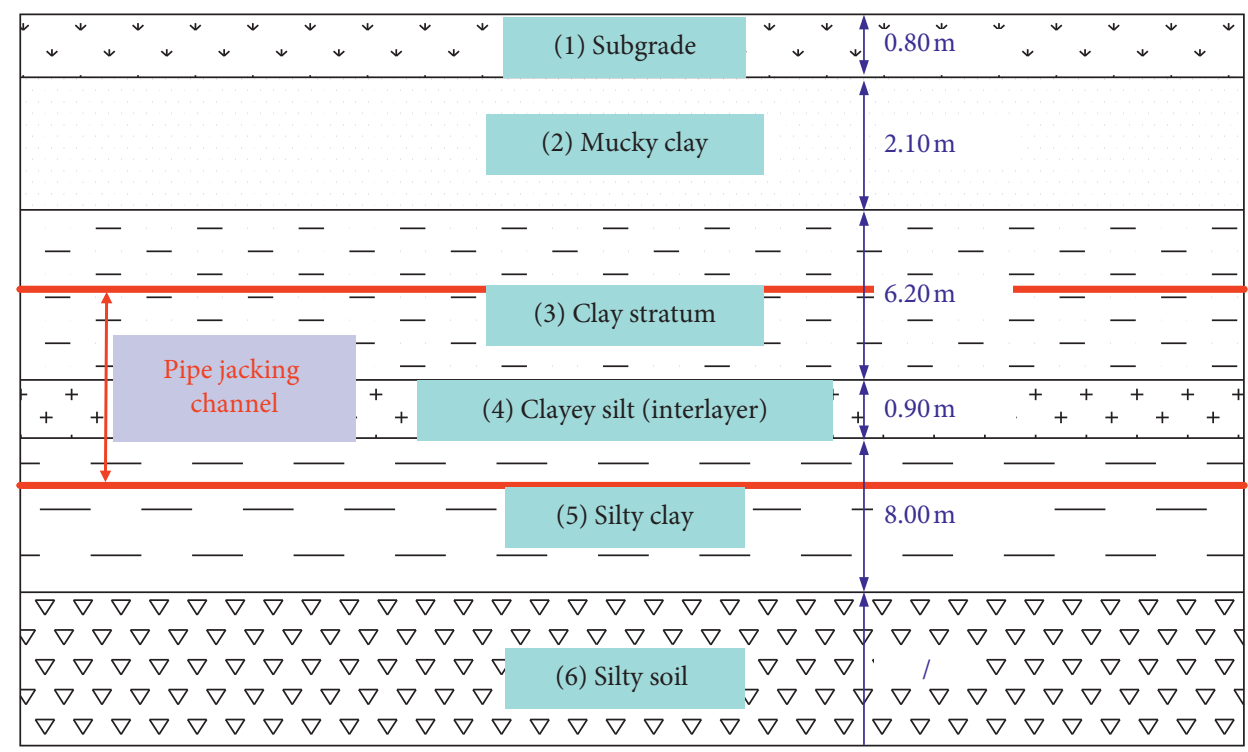

(a)

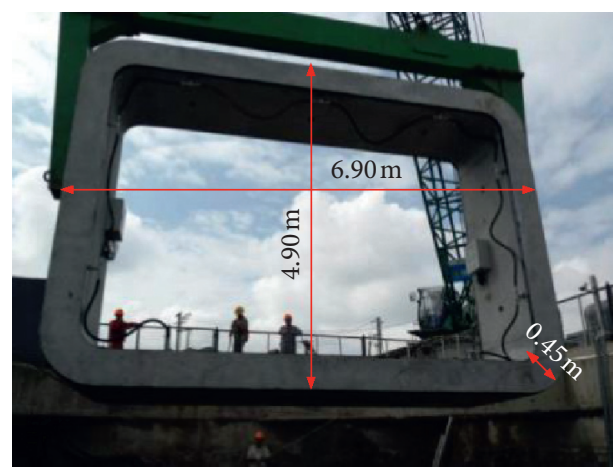

(b)

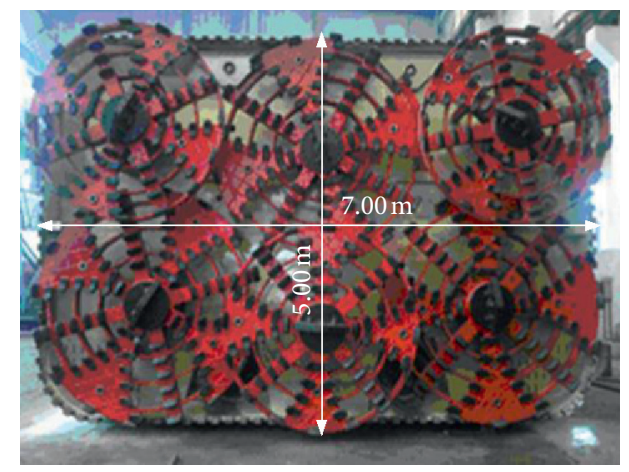

(c)

FIgURE 4: Soil distribution (location of pipe jacking channel), concrete pipe joints, and cutterhead of pipe jacking machine. (a) Soil distribution. (b) Concrete pipe joint. (c) Cutterhead of pipe jacking machine.

model of surface settlement, Peck's empirical formula and the calculation formula deduced in this paper are compared and analyzed, and field measured data are introduced. The data results are shown in Figures 9-12.
From the surface longitudinal settlement curve shown in Figures 9 and 10, it can be seen that the calculated values of surface changes in the uplift occurrence area, settlement stability area, and settlement rebound area by the empirical 
TABLE 1: Basic physical and mechanical indexes of foundation soil layer.

\begin{tabular}{|c|c|c|c|c|c|c|}
\hline Soil layer & $\begin{array}{l}\text { Thickness } \\
\text { (m) }\end{array}$ & $\begin{array}{l}\text { Natural capacity } \\
\left(\mathrm{kg} \cdot \mathrm{m}^{-3}\right)\end{array}$ & $\begin{array}{l}\text { Cohesive force } \\
\qquad(\mathrm{kPa})\end{array}$ & $\begin{array}{c}\text { Internal friction } \\
\text { angle }\left({ }^{\circ}\right)\end{array}$ & $\begin{array}{c}\text { Modulus of compression } \\
\text { (MPa) }\end{array}$ & $\begin{array}{l}\text { Poisson's } \\
\text { ratio }\end{array}$ \\
\hline Subgrade & 0.80 & 1850 & 15.00 & 21.50 & 11.82 & 0.35 \\
\hline Mucky clay & 2.10 & 1710 & 14.00 & 12.00 & 4.56 & 0.30 \\
\hline $\begin{array}{l}\text { Clay } \\
\text { stratum }\end{array}$ & 6.20 & 1790 & 16.50 & 18.50 & 5.89 & 0.35 \\
\hline Clay silt & 0.90 & 1830 & 8.00 & 31.00 & 7.29 & 0.37 \\
\hline Silty clay & 8.00 & 1940 & 39.00 & 21.00 & 8.93 & 0.35 \\
\hline Silty soil & - & 1970 & 2.00 & 32.50 & 11.82 & 0.38 \\
\hline
\end{tabular}

TABle 2: Friction coefficients [32].

\begin{tabular}{lcccccc}
\hline Soil types & \multicolumn{3}{c}{ Reinforced concrete pipe } & \multicolumn{3}{c}{ Steel tube } \\
& Dry & Moist & $\begin{array}{c}\text { Typical } \\
\text { value }\end{array}$ & Dry & Moist & $\begin{array}{c}\text { Typical } \\
\text { value }\end{array}$ \\
\hline Soft soil & - & 0.20 & 0.20 & - & 0.20 & 0.20 \\
Clay & 0.40 & 0.20 & 0.30 & 0.40 & 0.20 & 0.30 \\
stratum & & & & & & \\
Silt & 0.45 & 0.30 & 0.38 & 0.45 & 0.30 & 0.37 \\
Mucky clay & 0.35 & 0.20 & 0.28 & 0.35 & 0.20 & 0.27 \\
Silty clay & 0.40 & 0.30 & 0.35 & 0.40 & 0.30 & 0.35 \\
Gravel soil & 0.50 & 0.40 & 0.45 & 0.50 & 0.50 & 0.50 \\
\hline
\end{tabular}

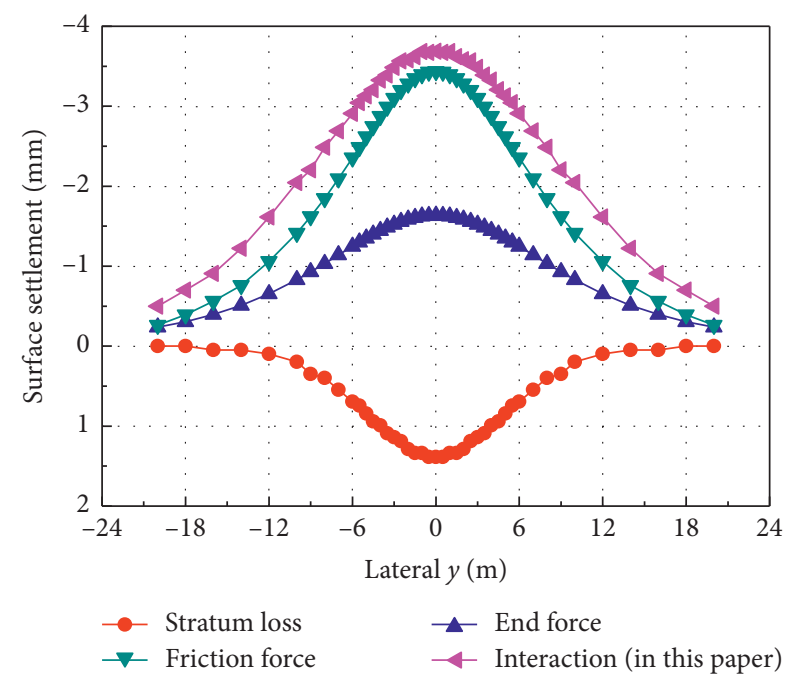

Figure 5: Lateral surface settlement $(x=3 \mathrm{~m})$.

method and the method in this paper are basically consistent with the measured values. However, in the sensitive area of subsidence, because the Peck empirical formula does not consider the change of vertical strata, the surface subsidence curve obtained shows a cliff-type change within the range of $-3 \sim 0 \mathrm{~m}$. There is no surface deformation on the surface above the excavation end, which is quite different from the measured value. However, the surface settlement curve calculated by this model is in good agreement with the measured variation trend.

Figures 11 and 12 show the lateral surface settlement curves at $x=3 \mathrm{~m}$ and $x=0 \mathrm{~m}$. Compared with the empirical method, the calculated results of this model are in good

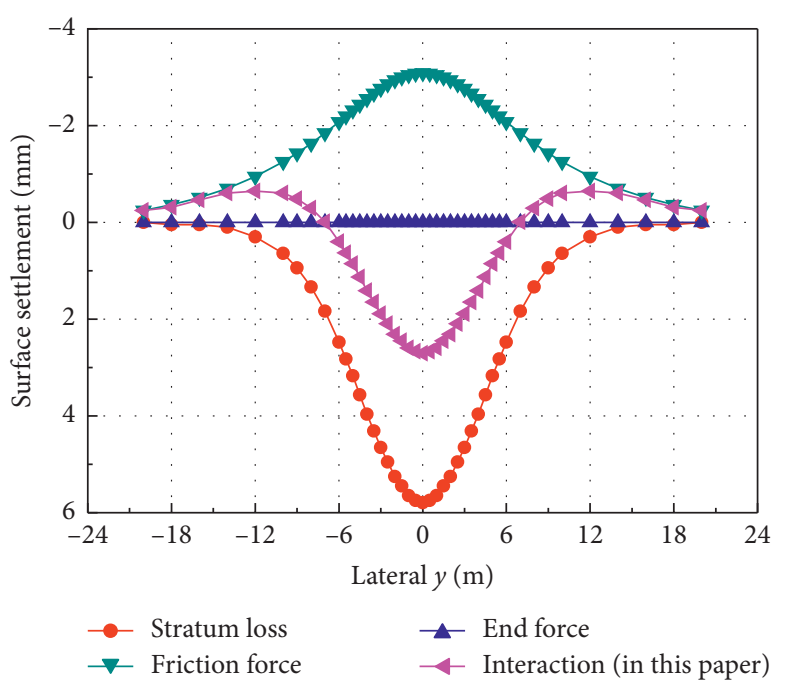

FIGURE 6: Lateral surface settlement $(x=0 \mathrm{~m})$.

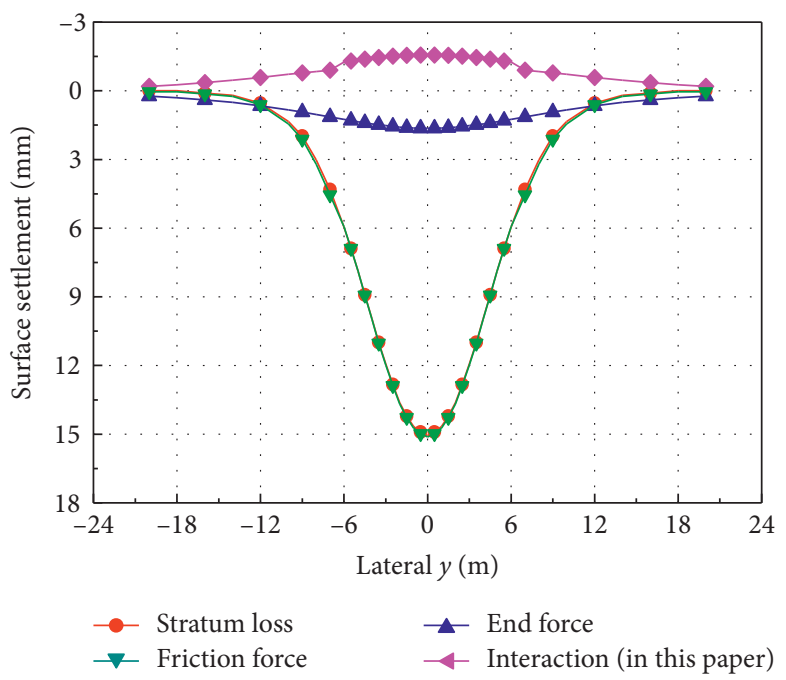

Figure 7: Lateral surface settlement $(x=-3 \mathrm{~m})$.

consistency with the field measured results. It can be seen from Figure 11 that the development trend of lateral surface settlement curve under the three conditions of empirical method, measured value, and joint action is basically similar, but the corresponding maximum settlement scale has significant differences, which are $29.92 \mathrm{~mm}, 19.43 \mathrm{~mm}$, and 


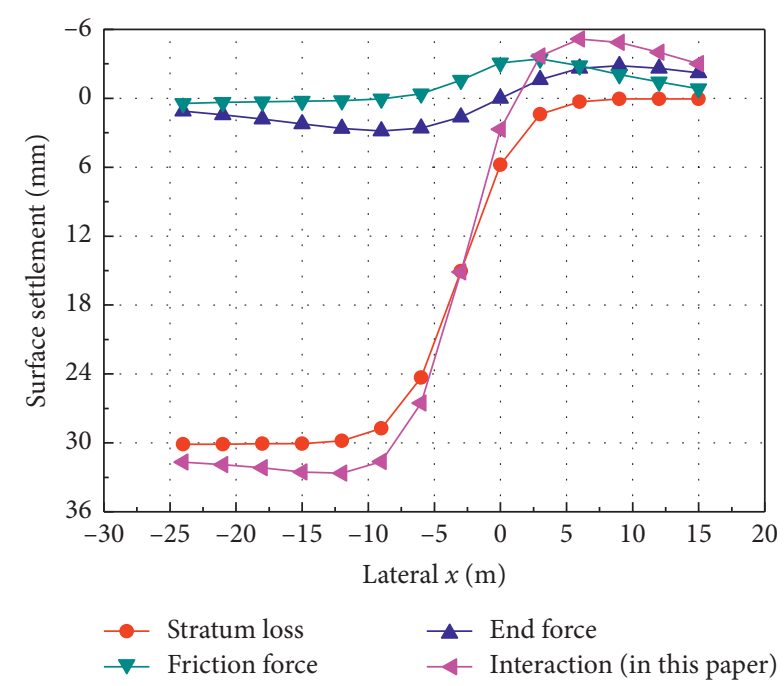

Figure 8: Longitudinal surface settlement $(y=0 \mathrm{~m})$.

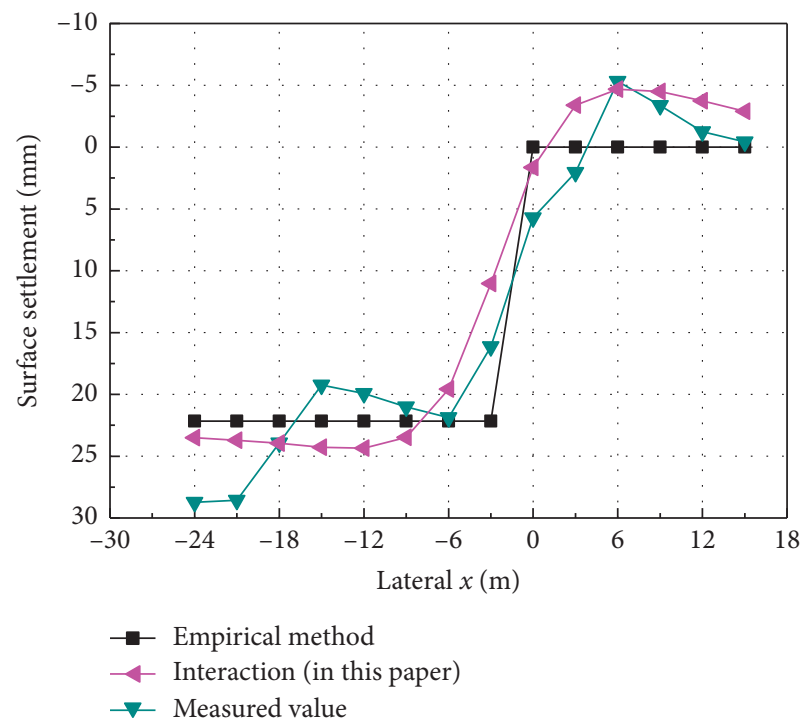

FIGURE 9: Longitudinal surface settlement $(y=-3.5 \mathrm{~m})$.

$15.13 \mathrm{~mm}$, respectively. Compared with the surface settlement value obtained by the empirical method, the surface settlement value calculated by this model is closer to the measured surface settlement value. The surface settlement curve at $x=0 \mathrm{~m}$ shows that the surface settlement value obtained by the empirical method is significantly lower than the measured value, which is not conducive to engineering safety analysis. The settlement value calculated by this model is close to the measured value.

It can also be seen from Figure 12 that the actual settlement value is $3 \sim 4 \mathrm{~mm}$ larger than the calculated value of this model within $5 \mathrm{~m}$ or so of the longitudinal axis of the pipeline. The main reason is that the stratum traversed by this project is mainly clay and the soil layer is relatively soft. In the construction process, the soil around the excavation face collapses to the excavation face, resulting in the microoverexcavation phenomenon, resulting in a slight gap

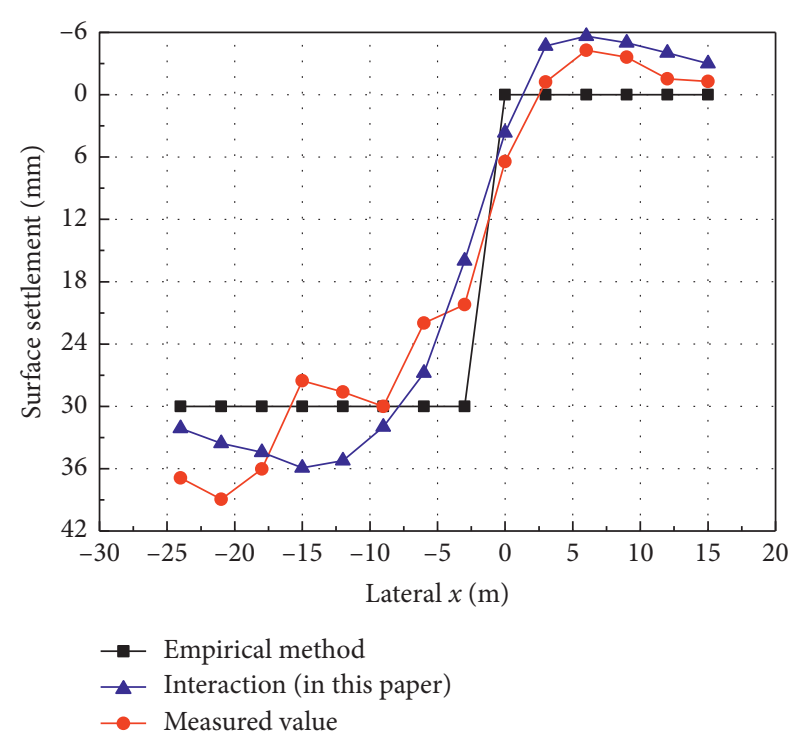

FIGURE 10: Longitudinal surface settlement $(y=0 \mathrm{~m})$.

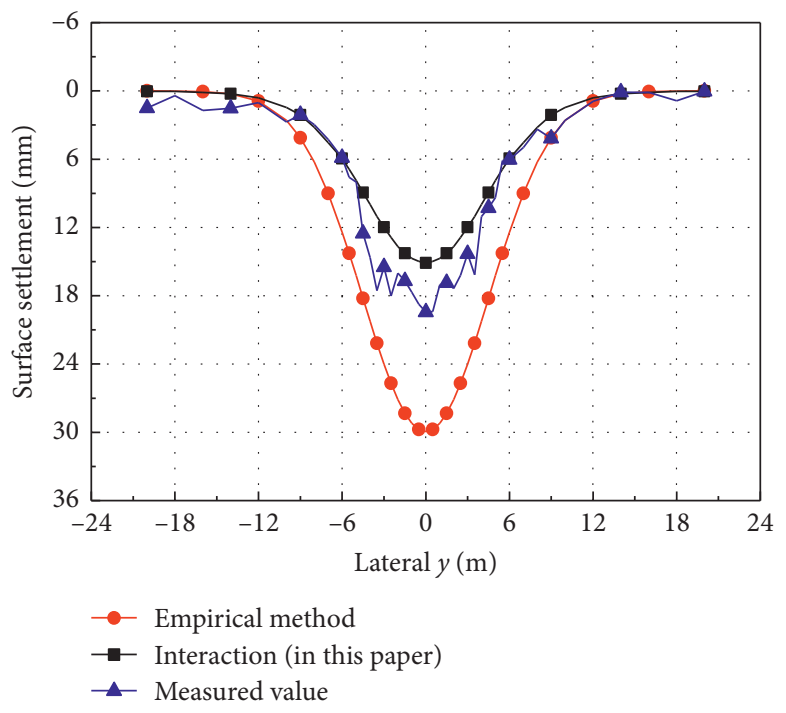

Figure 11: Lateral surface settlement $(x=-3 \mathrm{~m})$.

between the measured value and the calculated value of this paper.

It can be seen from the above analysis that the surface settlement amount calculated by this model has good practicability and reliability and has significant advantages over the empirical algorithm. The three-dimensional settlement trough on the surface during the construction of rectangular pipe jacking is drawn by using the calculation results of the model, as shown in Figure 13.

Figure 13 further illustrates the distribution law of surface changes caused by rectangular pipe jacking. (1) Large settlement is mainly concentrated in the range of 1.50 times of pipe joint width on both sides of pipe axis after excavation face, and the maximum settlement is in the range of 0.50 times of pipe joint width (directly above the pipe joint) on 


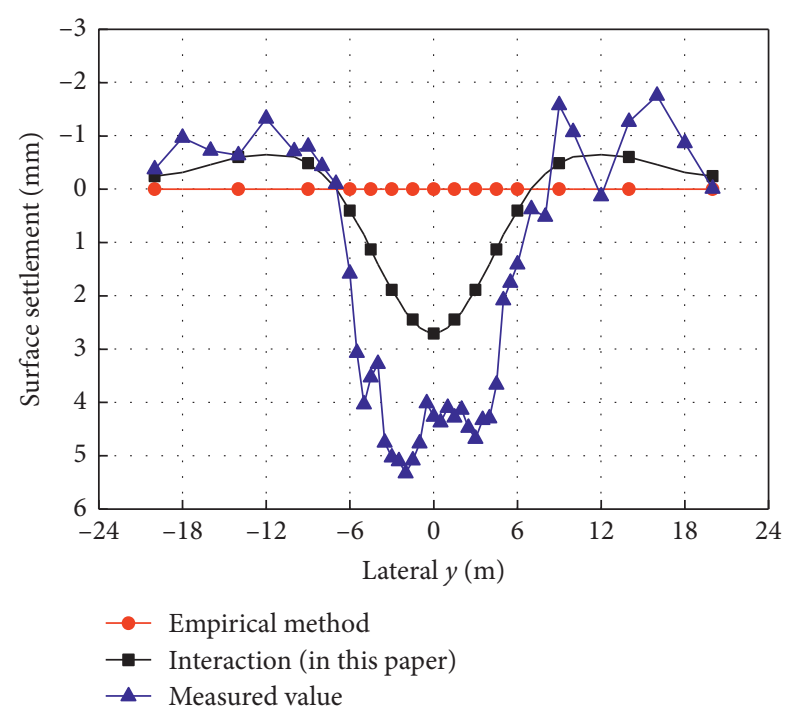

Figure 12: Lateral surface settlement $(x=0 \mathrm{~m})$.

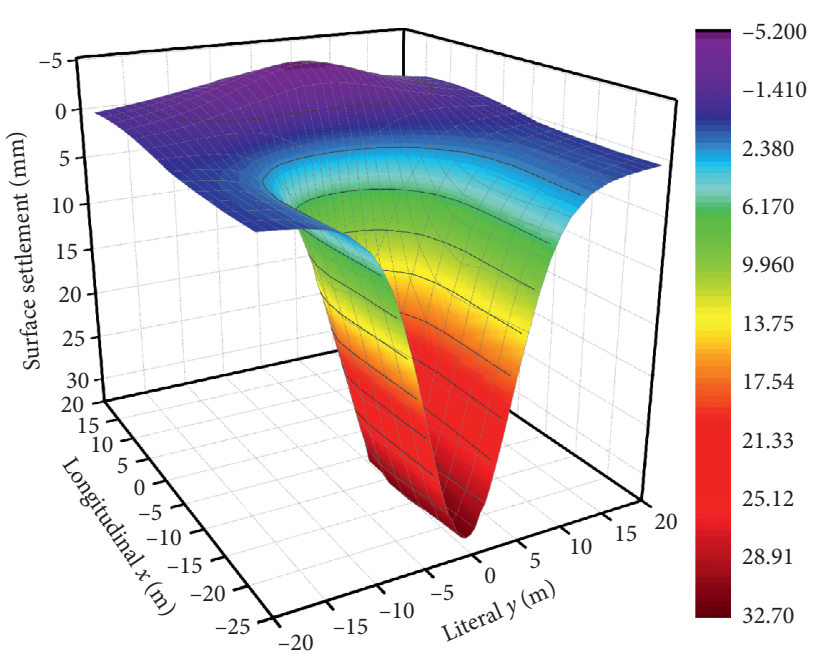

Figure 13: Surface three-dimensional settlement trough.

both sides of the axis. (2) The longitudinal direction of the uplift area is mainly concentrated within the range of $1.50 \mathrm{~m}$ to $15 \mathrm{~m}$ in front of the excavation, and the transverse range is within the width of 1.50 times of the pipe joints on both sides of the pipeline axis.

\section{Conclusion}

Based on the engineering background of Kunming metro line 6 , this paper studied the influence of soil loss, additional stress on end face, and friction force on surface settlement during the construction and arrived at the following conclusions:

(1) Based on Mindlin's solution and random medium theory, the superposition model of surface settlement caused by friction force, additional stress on end surface, and soil loss is proposed. Theoretical analysis shows that the vertical settlement curve of the surface is roughly in the shape of " $\mathrm{S}$," which can be divided into uplift occurrence area, sensitive settlement area, stable settlement area, and rebound settlement area. The measured data verify the rationality of the model. Because the three-dimensional displacement of soil is not considered by the empirical method, cliff-type changes appear in the sensitive areas of settlement, which is not consistent with the actual settlement.

(2) The front part of the rectangular pipe jacking area is shown as stratum uplift, while the rear part is shown as stratum settlement, and the dividing line is roughly located on the excavation face. Among the three main factors that cause the formation deformation in rectangular pipe jacking construction, friction force and additional stress on excavation surface mainly cause the stratum uplift in the front of the construction area. The soil loss mainly causes the stratum settlement at the rear of the construction area.

(3) Rectangular pipe jacking in weak strata causes the surrounding soil to move towards the excavation surface, making the actual overbreak value greater than the theoretical overbreak value, which is easy to cause micro-overexcavation. The large surface settlement is mainly concentrated within 1.50 times of the width of the pipe section on both sides of the pipe axis after the excavation face. The longitudinal settlement in the uplift area is mainly concentrated in the range of $1.50 \mathrm{~m}$ to $15 \mathrm{~m}$ in front of excavation, while the transverse settlement is mainly concentrated in the range of 1.50 times the width of pipe joints on both sides of the pipeline axis.

\section{Data Availability}

The data used to support the findings of this study are available from the corresponding author upon request.

\section{Conflicts of Interest}

The authors declare that there are no conflicts of interest regarding the publication of this paper.

\section{Acknowledgments}

The authors thank the National Natural Science Foundation of China (Grant no. 51578447), Fund of Housing Urban and Rural Construction Technology Research and Development Project Foundation of Shaanxi Province (Grant no. 2019-K39), Project Funded by China Postdoctoral Science Foundation (Grant no. 2018M643809XB), Natural Science Basic Research Program of Shaanxi (Grant no. 2019JQ-762), and the Natural Science Basic Research Program of Science and Technology Department of Shaanxi Province of China (Grant no. 2018JM5153). 


\section{References}

[1] Z. Song, J. Mao, X. Tian, Y. Zhang, and J. Wang, "Optimization analysis of controlled blasting for passing through houses at close range in super-large section tunnels," Shock and Vibration, vol. 2019, Article ID 1941436, 16 pages, 2019.

[2] Z. Song, G. Shi, J. Wang, H. Wei, T. Wang, and G. Zhou, "Research on management and application of tunnel engineering based on BIM technology," Journal of Civil Engineering and Management, vol. 25, no. 8, pp. 785-797, 2019.

[3] X. X. Tian, Z. P. Song, and J. B. Wang, "Study on the propagation law of tunnel blasting vibration in stratum and blasting vibration reduction technology," Soil Dynamics and Earthquake Engineering, vol. 126, Article ID 105813, 2019.

[4] Z. Song, G. Shi, B. Zhao, K. Zhao, and J. Wang, "Study of the stability of tunnel construction based on double-heading advance construction method," Advances in Mechanical Engineering, vol. 12, no. 1, p. 17, 2020.

[5] Z. P. Song, S. H. Li, J. B. Wang, Z. Y. Sun, J. Liu, and Y. Z. Chang, "Determination of equivalent blasting load considering millisecond delay effect," Geomechanics and Engineering, vol. 15, no. 2, pp. 745-754, 2018.

[6] P. Jia, B. Jiang, W. Zhao, Y. Guan, J. Han, and C. Cheng, "Calculating jacking forces for circular pipes with welding flange slabs from a combined theory and case study," KSCE Journal of Civil Engineering, vol. 23, no. 4, pp. 1586-1599, 2019.

[7] Z. P. Song, Y. Cheng, X. X. Tian, J. B. Wang, and T. T. Yang, "Mechanical properties of limestone from Maixi tunnel under hydro-mechanical coupling," Arabian Journal of Geosciences, 2020, in press.

[8] X. Ji, W. Zhao, P. Ni et al., "A method to estimate the jacking force for pipe jacking in sandy soils," Tunnelling and Underground Space Technology, vol. 90, pp. 119-130, 2019.

[9] P. Ni, S. Mangalathu, and Y. Yi, "Fragility analysis of continuous pipelines subjected to transverse permanent ground deformation," Soils and Foundations, vol. 58, no. 6, pp. 1400-1413, 2018.

[10] J. Wang, Q. Zhang, Z. Song, and Y. Zhang, "Creep properties and damage constitutive model of salt rock under uniaxial compression," International Journal of Damage Mechanics, 2019, in press.

[11] Y. W. Zhang, X. L. Weng, Z. P. Song, and Y. F. Sun, "Modeling of loess soaking induced impacts on metro tunnel using water soaking system in centrifuge," Geofluids, vol. 2019, 17 pages, 2019.

[12] C. Yin, "Hazard assessment and regionalization of highway flood disasters in China," Natural Hazards, vol. 100, no. 2, pp. 535-550, 2020.

[13] Y. Cheng, Z. Song, J. Jin, and T. Yang, "Attenuation characteristics of stress wave peak in sandstone subjected to different axial stresses," Advances in Materials Science and Engineering, vol. 2019, Article ID 6320601, 11 pages, 2019.

[14] Y. Chen, W. Zhao, J. Han, and P. Jia, “A CEL study of bearing capacity and failure mechanism of strip footing resting on $c-\varphi$ soils," Computers and Geotechnics, vol. 111, pp. 126-136, 2019.

[15] H. Wu, C.K. Yao, C.H. Li et al., "Review of application and innovation of geotextiles in geotechnical engineering," Materials, vol. 13, no. 7, p. 1174, 2020.

[16] J. L. Qiu, Y. Q. Lu, J. X. Lai, Y. W. Zhang, T. Yang, and K. Wang, "Experimental study on the effect of water gushing on loess metro tunnel," Environmental Earth Sciences, vol. 79, no. 9, pp. 1-12, 2020.
[17] Y. W. Zhang, Z. P. Song, and X. L. Weng, "A constitutive model for loess considering the characteristics of structurality and anisotropy," Soil Mechanics and Foundation Engineering, in press, 2020.

[18] D.-J. Ren, Y.-S. Xu, J. Shen, A. Zhou, and A. Arulrajah, "Prediction of ground deformation during pipe-jacking considering multiple factors," Applied Sciences, vol. 8, no. 7, p. 1051, 2018.

[19] W.-C. Cheng, J. C. Ni, J. S.-L. Shen, and H.-W. Huang, "Investigation into factors affecting jacking force: a case study," Proceedings of the Institution of Civil Engineers-Geotechnical Engineering, vol. 170, no. 4, pp. 322-334, 2017.

[20] C. Sagaseta, "Analysis of undraind soil deformation due to ground loss," Géotechnique, vol. 37, no. 3, pp. 301-320, 1987.

[21] A. Verruijt and J. R. Booker, "Surface settlements due to deformation of a tunnel in an elastic half plane," Géotechnique, vol. 46, no. 4, pp. 753-756, 1996.

[22] G. Wei, Z. Y. Huang, and R. P. Xu, "Study on calculation methods of ground deformation," Chinese Journal of Rock Mechanics and Engineering, vol. 24, no. supp.2, pp. 5808$5815,2005$.

[23] X. Han, The Analysis and Prediction of Tunneling Induced Building Deformations, Xi'an University of Technology, Xi'an, China, 2006.

[24] Y. Sun, F. Wu, W. J. Sun, H. M. Li, and G. J. Shao, "Two underground pedestrian passages using pipe jacking: case study," Journal of Geotechnical and Geoenvironmental Engineering, vol. 145, no. 2, Article ID 05018004, 2019.

[25] P. Zhang, S. S. Behbahani, B. Ma, T. Iseley, and L. Tan, “A jacking force study of curved steel pipe roof in Gongbei tunnel: calculation review and monitoring data analysis," Tunnelling and Underground Space Technology, vol. 72, pp. 305-322, 2018.

[26] C. Li, Z. Zhong, C. Bie, and X. Liu, "Field performance of large section concrete pipes cracking during jacking in Chongqing a case study," Tunnelling and Underground Space Technology, vol. 82, pp. 568-583, 2018.

[27] Q. Q. Lin, Analysis and Control of the Surface Deformation Caused by Rectangular Pipe Jacking Construction, Tongji University, Shanghai, China, 2008.

[28] F. J. Bing, X. Wang, N. Xi, and L. Fang, "3D numerical simulation of pipe jacking and its soil applicability study," Chinese Journal of Underground Space and Engineering, vol. 6, no. 7, pp. 1209-1215, 2011.

[29] J. X. Tang, L. S. Wang, J. I. Chang, and X. Y. Kou, "Threedimensional numerical analysis of ground deformation induced by quasi rectangle EPB shield tunneling," Journal of East China Jiaotong University, vol. 1, no. 33, pp. 9-15, 2016.

[30] C. W. W. Ng and H. Lu, "Effects of the construction sequence of twin tunnels at different depths on an existing pile," $\mathrm{Ca}$ nadian Geotechnical Journal, vol. 51, no. 2, pp. 173-183, 2014.

[31] R. D. Mindlin, "Force at a point in the interior of a semiinfinite solid," Physics, vol. 7, no. 5, pp. 195-202, 1936.

[32] N. X. Gao and X. Z. Zhang, Pipe Jacking Technique, China Architecture and Building Press, Beijing, China, 1984. 